\title{
TENDÊNCIAS E DESAFIOS DA PESQUISA EM EDUCAÇÁO COMPARADA: ENTREVISTA COM JÜRGEN SCHRIEWER
}

\author{
TENDENCIES AND CHALLENGES IN RESEARCHING \\ COMPARATIVE EDUCATION: INTERVIEW WITH \\ JÜRGEN SCHRIEWER
}

Entrevistadores:

\section{Danilo Romeu Streck}

Professor do Programa de Pós-Graduação em Educação da Universidade do Vale do Rio dos Sinos.

Maria Julieta Abba

Bolsista de pós-doutorado do Programa DOCFIX FAPERGS/CAPES no Programa de Pós-Graduação em Educação da Universidade do Vale do Rio dos Sinos.

Cláudia Schiedeck Soares de Souza

Professora do Instituto Federal do Rio Grande do Sul (Campus Bento Gonçalves/RS) e doutora em Educação pelo Programa de Pós-Graduação em Educação da Universidade do Vale do Rio dos Sinos.

\section{Entrevistado}

Jürgen Schriewer é professor emérito de Educação Comparada na Universidade Humboldt, em Berlim, onde atuou como decano da Faculdade de Educaçáo e como co-coordenador de redes de pesquisa sobre estudos interculturais em ciências históricas e sociais financiadas pela Agência Alemã de Pesquisa.. Ex-presidente da Sociedade de Educação Comparada na Europa, ele foi convidado como Professor Visitante em universidades em Paris, Estocolmo, Tóquio, Pequim, Cidade do México e Buenos Aires. Seus interesses de pesquisa centram-se na história comparada da educaçáo; pesquisa da sociedade mundial; bem como sobre a história e metodologia da pesquisa social comparada. A entrevista foi realizada no contexto de suas atividades como pesquisador visitante na Universidade do Vale do Rio dos Sinos- Unisinos, no mês de março de 20I8, com o tema: "Estudos internacionais e comparados em educação: Fundamentos, concepçóes e metodologias."

\section{Resumo}

A entrevista com Jürgen Schriewer, professor emérito da Humboldt Universität (Berlim) foi realizada no contexto de suas atividades como pesquisador visitante na Universidade do Vale do Rio dos Sinos-Unisinos, no mês de março de 2018, com o tema: "Estudos internacionais e comparados em educação: Fundamentos, concepçóes e metodologias". $\mathrm{Na}$ entrevista ele relata aspectos de sua biografia acadêmica e sua formaçáo como pesquisador em educação comparada. Compartilha o desenvolvimento de sua visão 
de estudos histórico-comparados, relacionando-os com as atuais tendências das pesquisas na área dos estudos comparados. Por fim, reflete sobre alguns desafios para o desenvolvimento da educação comparada na América Latina.

Palavras-Chave: educação comparada; internacionalização; neoinstitucionalismo; América Latina.

\section{Abstract}

The interview with Jürgen Schriewer, emeritus professor at the Humboldt Universität (Berlin) was held in the context of his activities as a visiting researcher at Unisinos University, in March 2018, on the topic "International and comparative studies in education: foundations, concepts and methodologies". In the interview, he reports aspects of his biography and his education as a researcher in comparative education. He shares the development of his vision of historical-comparative studies, relating them to the current trends of research in the area of comparative studies. Finally, he reflects on some challenges for the development of comparative education in Latin America.

KeYwords: comparative education; internacionalization; neoinstitutionalism; Latin America.

Entrevistadores: Gostariamos de agradecer sua generosidade por conceder esse tempo extra das suas atividades como pesquisador visitante da Universidade do Vale do Rio dos Sinos - Unisino, em projeto que contou com o apoio do CNPq. As perguntas nessa entrevista retomam alguns temas do seminário, de palestras e conversas informais deste periodo, e exploram possibilidades para ampliar nossa inserção na prática dos estudos comparados e na construção teórica da área. Para começar, seria importante saber um pouco mais de sua trajetória acadêmica. Especialmente, seu envolvimento com os estudos comparados em educação. Como os estudos comparados entram em sua vida acadêmica e o que eles aportam para o seu crescimento como pesquisador e educador?

Jürgen Schiewer: Bem, pode-se dizer que a abordagem comparativa, mais ou menos implícita, fez parte da minha vida pessoal e intelectual desde a infância. Pode parecer surpreendente, embora isso esteja ligado à história político-social da Alemanha no período pós-guerra. Nasci em Halle, uma antiga cidade universitária situada na antiga parte prussiana da Saxônia. A partir do veráo de 1945, estas zonas pertenceram à zona de ocupaçáo soviética, quer dizer, à posterior Alemanha Oriental. No entanto, devido às convulsóes nos finais da Segunda Guerra Mundial e ao caos político 
e administrativo do pós-guerra, minha mãe decidiu, em I948, mudar-se com seus filhos para a Alemanha Ocidental, onde meu pai ainda vivia em um campo de prisioneiros de guerra britânico. No outono de 1948, cruzamos a linha de demarcaçáo. Não era uma fronteira verdadeira, não era o muro, mas uma linha de demarcaçáo ${ }^{2}$. Lembro-me muito bem que éramos um grupo de 15 a 20 pessoas liderados por um guia, que secretamente nos conduzia pelas florestas da Turíngia. Quando os carros soviéticos se aproximavam com os soldados, nós nos escondíamos na neve para podermos ter a chance de finalmente alcançar o lado ocidental. Ao final de novembro de 1948, vi meu pai pela primeira vez. Eu tinha 6 anos e ele era um homem desconhecido para mim. Importante destacar o papel extraordinário desempenhado durante todo esse tempo, nesses processos, pelas mulheres que se obrigaram a manter a vida familiar, sustentar a vida, etc. Bem, chegamos então à Westfália ${ }^{3}$ e, no ano seguinte, nos mudamos para a Renânia ${ }^{4}$, onde passei toda minha infância e juventude e os primeiros anos de meus estudos universitários. Para minha irmã e para mim, a perda de nossa casa natal e o brusco reassentamento da Alemanha oriental, essencialmente luterana, para a Renânia ocidental, e profundamente católica significou algo como um choque cultural. A Renânia não era minha região natal. Nossa família se considerava forasteira na Renânia. Não falávamos o dialeto específico e qualquer um podia perceber claramente que éramos pessoas vindas da parte oriental da Alemanha. Isso quer dizer que, mesmo dentro do meu próprio país, eu era um pouco estrangeiro. Lembro-me muito bem das discussóes familiares em torno da mesa, durante o jantar ou o almoço, quando éramos sempre nós e os outros... nós e os outros. Exatamente como o título de um livro publicado mais tarde por Edmund King, "Nossas Escolas e Outros", nós e os outros. Esse tipo de configuração é quase como o fundamento de não pertencimento, o que eu tentei explicar um pouco no seminário aqui na Unisinos. Mais tarde veio a habilitação profissional. Comecei meus estudos na Universidade de Bonn. Inicialmente, queria estudar Filosofia e Germanística ${ }^{6}$. Contudo, um professor de latím, de mais idade, já com mais de 60 anos que veio da Áustria antiga e foi oficial na Primeira Guerra Mundial, me disse que eu deveria estudar alguma coisa mais séria e não Filosofia (risos). Eu tinha um interesse particular pelo francês, assim o escolhi como uma terceira língua, e cujos estudos eram completamente gratuitos. Comecei com o 
latim, depois o inglês e então escolhi o francês. Depois, comecei a estudar Romanística na Universidade de Bonn. E a Romanística, enquanto estudo das línguas e literaturas românicas, geralmente cobre Francês, Espanhol, Italiano, Romano, Romeno, Português, etc. Também tive a felicidade de encontrar, já em Bonn, professores de literatura comparada, que tinham estabelecido novamente a cátedra de literatura comparada em uma universidade da Alemanha Oriental.

\section{Entrevistadores: Isso ocorreu em que ano?}

Jürgen Schriewer: Em 1963. Recordo-me bem de Horst Rüdiger ${ }^{7}$, um sujeito muito intenso que fundou uma revista de literatura comparada e da qual gostava muito. Ele acabou me estimulando e me inspirando muito mais do que todos os seminários e conferências de que participei sobre Germanística ou Romanística. Um ano depois, mudei para a Universidade de Würzburg ${ }^{8}$, no norte da Baviera, como era habitual nestes tempos. As pessoas mudavam de uma universidade para outra e novamente tive satisfação de poder estar em contato com professores germanistas suíços, que desenvolviam a sua disciplina de uma forma intencionalmente comparada. Era tanto o caso da literatura alemá moderna, sempre examinada dentro do marco histórico comparativo na relação mais ampla com as literaturas europeias clássicas e moderna, como o caso do professor de literatura medieval que estudava sistematicamente as relaçóes de influência da literatura medieval francesa, as suas tradiçóes no alemão, suas adaptaçóes, suas elaborações mais completas e mais poéticas, particularmente o mito antigo de Tristão e Isolda, que na minha opinião é a obra absolutamente mais majestosa de Gottfried von Strassburg"9 , uma das composiçóes literárias mais poéticas da língua alemã, no alto alemão medieval o 'alemánico', falado no sudoeste do país. ${ }^{10}$ Os Alemanni se fixaram no sudoeste da Alemania, a maior parte da atual Suíça y Alsácia ${ }^{\mathrm{II}}$, e é por isso que os franceses chamavam seus vizinhos limítrofes de alemáes, mas o termo designa apenas uma parte linguística. Quase toda a literatura alemã da Idade Média foi produzida e redigida no dialeto alemânico. E é quase uma música em forma de linguagem.

Então, durante quase todos os meus estudos literários, ou histórico-literários e filosóficos, eu já estava preparado para estabelecer relaçôes com os 
outros, uma espécie de interesse comparado. Também a formação de professores do ensino médio, nessa época, cotejava estudos em seus respectivos temas. Eram estudos de Germanística e Romanística para poder mais tarde ensinar o alemáo, a literatura alemá e a francesa, sendo do mesmo modo obrigatório cursar as disciplinas de Pedagogia, Ciências da Educação e Filosofia. Realizei meus primeiros exames em Filosofia e Pedagogia em Würzburg. O professor de Pedagogia desta época me sugeriu que quando eu fosse à França, para dar sequência aos meus estudos, observasse um pouco as reformas que aconteciam por lá naquele momento. Quando retornei, apresentei-lhe um informe sobre as discussóes da reforma educacional na França e, então, esse professor me ofereceu uma posição como pesquisador depois que eu realizasse os exames formais ${ }^{12}$. Depois de esperar mais de dois anos para que eu pudesse terminar e passar nos meus exames, pois eram provas muito difíceis na Baviera, ele manteve sua promessa e foi muito correto nesse sentido. Uma semana depois, ainda um pouco cansado de me preparar para os tais exames, que consistiam de avaliaçóes escritas e orais durante um período de 5 meses aproximadamente, iniciei minhas atividades no Instituto de Ciências da Educação como assistente de pesquisa e escolhi como tema minha tese de doutorado as reformas nas universidades francesas. Um tema que no final dos anos 60 era muito atual. Com uma bolsa do governo francês, me estabeleci em Paris para adiantar minha pesquisa por alguns meses. No retorno conheci minha esposa, fomos morar juntos e terminei minha tese de pouco mais de 500 páginas. Um pouco descritiva, claro, mas bastante abrangente. Depois de obter o doutorado me perguntei: bem, o que você vai fazer a partir de agora? O professor de literatura medieval alemá propôs que eu me juntasse à sua equipe de pesquisa porque ele sabia de meus conhecimentos linguísticos no francês e alemáo. Contudo, não me agradava dedicar toda minha vida à Filologia, entendida no sentido estrito. Eu também podia entrar na carreira das Ciências da Educação, como estimulou meu professor de Pedagogia, mas esse é um campo um tanto impreciso. E o que me interessou, naquela época, foi a abertura ao mundo que a educação comparada possibilitava. Eu tinha começado a ler publicaçóes neste campo realizadas por outros professores desse tema na Alemanha. Estava muito interessado no conhecimento da Europa Oriental e seus diferentes países. Foi por isso que, depois de obter meu doutorado sobre as universidades francesas, decidi dedicar- 
me à educação comparada. Esse assunto era emergente, mas já aos 30 anos de idade eu olhava para o meu crescimento pessoal e depois acadêmico, sempre observando questôes comparativas: nós e os outros. Interessante, não é? Como se forma uma perspectiva naturalmente comparada.

Entrevistadores: Muito obrigado por compartilhar essas experiências de sua vida e formação. Provavelmente foi assim que, na França, Durkheim entra muito fortemente em sua vida acadêmica...

Jürgen Schriewer: Depois de conseguir meu primeiro cargo de professor em Frankfurt estudei muito o trabalho durkheimiano. Na realidade, eu era fascinado por Emilio Durkheim e, inclusive, foi até possível, em Frankfurt, nos anos 1970 ou I980, organizar um seminário com IO a I2 alunos para estudar e debater seus textos em francês, o que atualmente seria impossível.

Entrevistadores: E agora, Professor Schriewer, dando um salto de Durkheim para os momentos atuais. Como você vê a educação comparada, hoje? Quais as principais tendências, a partir dessas origens com Durkheim?

Jürgen Schriewer: Gostaria de começar com a citação de uma análise de história comparada cujo tema eram os processos de alfabetização e o papel desempenhado pela escola primária em certas partes da Alemanha e da França. Esse estudo foi realizado por um historiador francês, que ainda vive em Berlim, e ele assim se refere ao tema: "Nada é mais fascinante que o estudo histórico comparado, mas nada é mais difícil”. Embora essa seja uma percepção muito perspicaz e pertinente sobre a tarefa comparada, infelizmente, o que observo durante os grandes congressos, não só na Alemanha, mas na Europa, nos Estados Unidos, ou seja, internacionalmente, é que muitas pessoas estão trabalhando com a educação comparada como se fosse a matéria mais fácil do mundo. $\mathrm{Na}$ verdade, esse é um dos campos de estudo educacional mais difíceis e pressupóe conhecimento da linguagem, bem como de diferentes áreas com seus domínios culturais e intelectuais específicos. Pressupóe, ainda, uma enorme sensibilidade com relação às diferenças, às particularidades culturais. 
Além, é claro, do conhecimento teórico necessário para poder conceituar, para explicar de maneira razoável tudo isso, para chegar a conclusôes convincentes. Nesse sentido, no âmbito da educação comparada, de maneira geral, da forma como ela se apresenta em grandes conferências mundiais, encontramos muitas propostas, apresentaçôes e documentos que não despertam grande interesse. São trabalhos descritivos vinculados a algumas interpretaçôes fáceis e que favorecem posições reformadoras. Por isso, existe um choque entre a realidade e um campo fascinante que se desenvolve, assim, digamos, de forma um pouco insuficiente. Assim se amplificaram todos os estudos que estivemos discutindo durante dois dias sobre comparaçóes simples e complexas, sociocentrismo e perspectivismo $^{13}$ e toda esta série discussóes que finalmente nos auxiliam a identificar o sociológico e epistemológico. Ao seguir uma lógica epistêmica, a educação comparada parece estar sendo muito mais materializada pelos sociólogos do que pelos educadores, principalmente em certos estudos norte-americanos, o que, de certa forma, é instigador. Posso me referir a teóricos como Erwin Epstein ou Joseph Farrell, grandes especialistas da América Latina, e também aos nossos amigos de Stanford, da corrente neoinstitucionalista ${ }^{14}$, tais como Francisco Ramírez, natural das Filipinas. Ramirez mudou-se para os Estados Unidos e compartilha um pouco do profundo encontro pessoal com diferentes áreas de estudo, sendo professor de educação comparada.

Entrevistadores: Confirma-se a importância da trajetória pessoal nas escolhas profissionais.

Jürgen Schriewer: Não tenha dúvida! Os Ramirez são uma das grandes famílias filipinas de origem castelhana. Gostaria de destacar também os historiadores dedicados à história comparada como Fritz Ringer ${ }^{15}$, de origem alemã, mas que emigrou para os Estados Unidos com sua família aos 6 ou 7 anos e, talvez por isso, dedicou-se durante toda a sua vida a temas comparativos entre a Europa e a América do Norte, como por exemplo, a explicação da trajetória político-ideológica da Alemanha dentro desse marco das sociedades ocidentais. Um grande historiador! Um de seus livros mais famosos chama-se O Declínio dos Mandarins Alemães. Os grandes catedráticos das Ciências Sociais dividiram-se entre uma corrente mino- 
ritária dos modernistas, uma corrente majoritária dos conservadores e um grupo de pessoas sem vinculação alguma. E alguns dos grandes nomes de Ringer eram Max Weber, Georg Simmel, enfim, os modernistas. Então, o encontro com historiadores comparativos e todo o resto também acabaram me estimulando a perceber a diferença entre uma reflexão reformadora internacional e uma ciência da educaçáo comparada propriamente dita. Isto se mostra claramente em meus trabalhos desenvolvidos durante minha estada em Frankfurt, por exemplo obras que tratavam das estruturas da educação profissional e vocacional na França e na Alemanha. Mais tarde apresentei um grande projeto de pesquisa sobre a organização universitária e o desenvolvimento teórico-conceitual da Pedagogia ou da Ciência da Educação também na França. Enfim, existia muita ênfase nas comparaçóes franco-alemãs. Quase nunca publiquei estudos de caso sobre um país apenas. Sempre procurei introduzir a comparação sistemática combinada com uma abordagem histórica. Dessa forma, desenvolvi pessoalmente, com meu estilo de trabalho, a perspectiva de estudos histórico-comparados conceituais, e na medida do possível, de acordo com os referenciais teóricos estabelecidos.

Entrevistadores: Neste sentido, como a sua visão se relaciona com os neoinstitucionalistas? Como dialoga com a concepção neoinstitucionalista?

Jürgen Schriewer: Numa primeira fase de leituras, portanto, de recepção, achei essa perspectiva muito instigante, muito pertinente. Existe um sentimento ambíguo quando se lê esses textos, pois sempre parecem absolutamente convincentes. Contudo, quando você reflete sobre eles e quando se confronta essas leituras com a realidade e seus próprios conhecimentos, os questionamentos aparecem. Quando eu já estava em Berlim, começamos a estruturar uma pesquisa longitudinal, mais de oito décadas, em grande escala sobre o desenvolvimento das externalizaçôes em diferentes áreas, com o objetivo de examinar certas hipóteses da abordagem neoinstitucionalista.

Entrevistadores: Poderia falar um pouco da externalização, como um conceito fundante em sua reflexão? 
Jürgen Schriewer: Esse conceito foi desenvolvido no final dos anos 8o. O primeiro ensaio onde tentei desenvolver o conceito usando todas as fontes retiradas da Sociologia e da Antropologia Histórica do conhecimento foi apresentado em uma Festschrift ${ }^{16}$ dedicado a Niklas Luhmann, discutido pessoalmente com ele. Participei de um evento acadêmico em homenagem aos seus 60 anos e foi um debate muito produtivo. Mais tarde tive o privilégio de descobrir, cada vez mais, em suas notas de publicaçóes posteriores, bem (risos)... uma referência para Jürgen Schriewer, nos ensaios, artigos ou livros. Isso foi, de certa forma, intermediado por um colega de Hamburgo, Karl-Eberhard Schorr, que foi coautor de Luhmann, talvez seu mais íntimo amigo pessoal. Luhmann era uma pessoa muito fechada, muito seca, um jurista, um administrador, que podia parecer um burocrata, e que ao mesmo tempo possuía uma capacidade extraordinária de elaboração, e também para desenvolver e combinar dados, lidar com os mesmos em quadros teóricos, de jogar com diferentes hipóteses, etc. Karl-Eberhard Schorr, um herdeiro de uma grande família industrial de Hamburgo. Schorr morava em sua casa, à beira do Rio Elba, e, eventualmente, convidava pequenos grupos de aproximadamente vinte e cinco pessoas da área para debater temas que pudessem ser de interesse compartilhado por Luhmann. Karl-Eberhard Schorr, esse personagem impressionante, operou como um mediador para certos especialistas das ciências da educação conhecidos por seus interesses teóricos, repassando a Luhmann todas as nossas observaçóes, já que eles trocavam reflexôes permanentemente. Dessa forma, desenvolvi a primeira versão básica, no final dos anos 80 , que foi mais tarde retomada para suavizar um pouco todos os conceitos abstratos, para enriquecê-la com um conteúdo mais empírico, bem como delinear uma forma de incorporar outras sociedades e o desenvolvimento internacional como um argumento dentro das discussões sobre políticas educacionais. Esse conceito também pode ser observado na esfera política, onde muitos políticos reinterpretam épocas históricas e figuras da história trazendo-os como pressupostos para o debate atual. E isso pode ser encontrado em muitas áreas. Por exemplo, li recentemente um artigo sobre novas formas de organização na carreira acadêmica de jovens pesquisadores em universidades alemãs e concluí que é importante compatibilizar nossas carreiras acadêmicas no cenário internacional. Mas: o que são carreiras acadêmicas no contexto internacional? Elas não existem! Elas 
são muito diferentes na Grã-Bretanha, na França, nos Estados Unidos, em todas as partes do mundo. Seria preciso adaptá-las para torná-las compatíveis com carreiras internacionais. Essa é uma maneira insensata de pensar e que contribui para alinhamentos fáceis que levam ao desenvolvimento de tendências dominantes, mas que não correspondem à realidade. Nesse sentido, me opus cada vez mais à discrepância com que se administra a diversidade de instituiçóes, de práticas, de modelos, já que me parece importante evitar exatamente essas tendências. Há aproximadamente Io anos fui convidado para participar do Fórum de Pequim, um grande congresso internacional, especialmente porque reúne representantes de todos os países asiáticos. Um cientista político norte-americano, de origem alemã, apresentou um documento concluindo que "há virtude na diversidade". Essa é uma citação que retomo frequentemente nos meus escritos: "há virtude na diversidade". É muito importante manter uma pluralidade de soluçôes para se evitar as armadilhas de uma forma única e simples de pensar.

Entrevistadores: Os sistemas autorrefenciais não tendem a se diluir [verschmelzen] atualmente?

Jürgen Schriewer: Não, acho que não, a não ser que seja para ampliar horizontes, para evitar divergências, para expandir, para enriquecer um pouco seus pontos de referência, seus significados complementares, mas que podem contribuir para certos modos de pensamento único. Esse é o perigo.

Entrevistadores: Então, o que existe de fato é uma ampliação das possibilidades de externacionalização? Com mais possibilidades de referências...

Jürgen Schriewer: Sim, a citação "existe virtude na diversidade" é mais ou menos a linha de argumentação geral do Plano para uma Antropologia Comparativa, texto de Wilhelm von Humboldt ${ }^{17}$. Antes mesmo do desenvolvimento de todas as metodologias necessárias para estabelecer comparaçóes sistemáticas, ele já possuía uma visão do grande campo que estava estabelecido em suas pesquisas linguísticas. Ele teve uma visão preliminar e queria traçar comparaçôes sistemáticas para possibilitar explicaçôes cau- 
sais, enfatizando ao mesmo tempo que todos os objetos históricos, pessoas, grandes pensadores de todos os países de todas as épocas, períodos históricos, sociedades, culturas, que todos esses objetos tinham um valor próprio que cabia preservar e não unificar. Diz ele que o ideal da humanidade é atingido a partir da grande variedade de objetos históricos. É quase como se nós fossemos os guardiôes da riqueza da humanidade. É um texto maravilhoso que estudei com meus alunos algumas vezes e a cada leitura descobria novas facetas em termos de significados. É possível fazer comparações esquemáticas não para unificar todos esses objetos, mas preservá-los. $\mathrm{O}$ ideal da humanidade é sua enorme riqueza.

Entrevistadores: Parece que sempre há os paises de referência, regióes de referência. Na América Latina se critica o que nós aqui chamamos "eurocentrismo", que seria exatamente uma critica a essa possibilidade de diversidade. Como você vê o papel da Europa hoje nesse contexto internacional? E eventualmente, como percebe a América Latina neste grande mundo?

Jürgen Schriewer: Indiscutivelmente, vivemos situaçôes de certa dependência intelectual. No caso da América Latina, percebe-se a dependência da Europa e também dos Estados Unidos; e na Europa, após a Segunda Guerra Mundial, é possível traçar também certas relaçóes de dependência intelectual de tudo o que veio dos norte-americanos, em todos os campos do esporte, da música, da vida cultural, dos filmes e também nas correntes de pesquisa Náo estou certo de que os europeus, profissionais acadêmicos e universitários, já tenham conseguido, hoje em dia, assegurar suas próprias posiçóes e tradiçôes. Num certo momento, os franceses tiveram mais destaque com seus grandes intelectuais, suas filosofias, mas isso parece haver terminado. Durante as últimas duas décadas, a França não tem desempenhado um grande papel. No que se refere ao mundo acadêmico da Alemanha, as universidades alemãs poderiam ter desempenhado um papel muito maior se não estivessem amarradas de forma tão profunda a tantas restriçôes administrativas e burocráticas. Penso que o problema é exatamente o fato de que elas são quase todas públicas, geridas pelos governos de diferentes Estados federados (os Länder), com sua visão estreita, uns burocratas que não conhecem o mundo. Além de toda a 
legislação universitária existente, os acórdãos do Tribunal Constitucional de Karlsruhe ${ }^{18}$, que impóe outras restriçôes. Com tudo isso, eles não são livres para desenvolver seus potenciais. E, nesse sentido, elas se encontram em uma situação de dependência que somente depois do governo de Schröder ${ }^{19}$ e de seu ministro federal de ensino superior, conseguiram mudar um pouco o panorama. É o chamado programa Iniciativa para a Excelência ${ }^{20}$, processo realizado para estimular certa competitividade entre as universidades, que, tradicionalmente, eram valorizadas de forma igualitária. Pela Iniciativa para a Excelência, se introduziu uma forma de competição para colocar em destaque algumas universidades alemãs que tenham maior alcance internacional. Assim, no transcurso de menos de duas décadas, surgiram as universidades de maior destaque: as duas universidades de Munique, a Universidade Técnica de Munique ${ }^{21}$ e a Universidade Ludwig-Maximilian (de caráter geral) ${ }^{22}$. Também as duas universidades de Berlim, a Universidade Livre de Berlim ${ }^{23}$ e a Universidade de Humbold ${ }^{24}$. O que é um enorme salto em se considerando que em 1991 Humboldt era uma universidade da Alemanha Oriental. Uma mudança radical, de pessoal, de marcos de referência, de conteúdo, de pesquisa. É incrível. Mas hoje, certas universidades alemãs ocupam boas posiçóes, segundo o ranking da Times Higher Education ${ }^{25}$. Elas são a Universidade Tecnológica de Karlsruhe ${ }^{26}$, talvez o melhor da Alemanha, além da Universidade Técnica de Munique e, também, Heidelberg ${ }^{27}$. Então, duas de Munique; duas de Berlim, Karlsruhe, Heidelberg, e dentro de certas flutuaçóes, Freiburg ${ }^{28}$ e Tübigen ${ }^{29}$. Infelizmente, a Universidade de Göttingen ${ }^{30}$ que foi o exemplo histórico muito destacado da modernizaçáo se movimenta neste ranking na direção descendente, enquanto que a Universidade Técnica de Dresden ${ }^{31}$ está subindo nessa avaliação. Nesse sentido, acredito que esse processo nos auxiliará a dar mais um passo rumo a um desenvolvimento de maior independência institucional, de pujança na pesquisa, de visibilidade e, portanto, também de autonomia na expansão dos marcos teóricos e filosóficos. Penso que a Europa tem se esforçado para se manter numa posição mais independente durante as duas últimas décadas através de uma evolução sustentável, estimulada ainda mais pelo desenvolvimento dos Estados Unidos. Quando Angela Merkel retornou da Cúpula do G-7 na Sicília, no ano de 20I7, depois de ter se reunido por três vezes com um certo cavalheiro americano (risos), 
ela declarou publicamente que os tempos em que podíamos confiar nos Estados Unidos são, até certo ponto, coisas do passado. A Europa deve lidar com os seus próprios problemas de forma muito mais completa do que estávamos acostumados a fazer. São as consequências de longo prazo das guerras desastrosas do século passado.

Entrevistadores: E qual é o papel, dentro disso, que o processo de Bolonha desempenha?

Jürgen Schriewer: Antes, deixe-me responder à segunda parte da sua questão anterior sobre a América Latina. Tenho um professor amigo na Universidade de Sydney, na Austrália, muito importante também, filho de uma família de imigrantes judeus, descendente dos territórios poloneses do Império dos Habsburgo. Após a Primeira Guerra Mundial, a família se mudou para Viena e, depois de 1938 , acabaram tendo que emigrar para a Austrália. Desde os anos 1960, alguns de seus membros regressaram à Europa. Assim, este amigo, depois de terminar seus estudos de pós-graduação na Universidade de Londres, como tantos outros imigrantes, se dedicou particularmente à educaçáo comparada.

Um dia ele me disse que os europeus, em especial, os alemães, possuem uma relação idealizada com a América Latina, uma visão romântica. E isso, até certo ponto, é verdade. Carlos Fuentes ${ }^{32}$ aponta em um de seus livros que, para os europeus, a América Latina é quase o sonho inacabado do Renascimento Europeu e me parece convincente (risos). Combinar esse sonho com a realidade às vezes é difícil. $\mathrm{O}$ sonho se estabelece quando não se tem contato com a América Latina. No momento em que se tem uma convivência com a realidade surge uma pequena desilusão. Portanto, são relaçôes muito complexas entre projeção, idealização e alguma decepção, especialmente no que diz respeito ao desenvolvimento político e econômico das últimas décadas, que é desastroso. Sempre disse aos meus colegas, minha família, minha esposa, como é possível que um país tão lindo, tão avassalador quanto o México, esteja em uma situação política, econômica ... não tanto econômica, mas política e ideológica tão desastrosa quanto o México da atualidade, com as máfias das drogas, crimes, etc. É um desenvolvimento trágico, bem, vocês sabem muito melhor do que eu o grau de dificuldades que se coloca quando se trata de melhorar as coisas. 
Entrevistadores: São observaçóes importantes para estudos comparados. Parece que a atenção ao desenvolvimento histórico oferece luzes importantes para nosso trabalho, aqui.

Jürgen Schriewer: Com certeza. Deixe-me apresentar também uma comparação histórica. Vocês estão familiarizados com a Guerra dos Trinta Anos que aconteceu entre I6I8 e I648 - predominantemente - embora náo exclusivamente - entre príncipes católicos e protestantes na Alemanha e na qual participaram tanto os imperador dos Habsburgo como países como Suécia, França, Espanha e outros. Durante meus anos de estudo em Würtzburg pude avaliar as consequências de longo prazo desta guerra. Usando um exemplo: A primeira grande igreja da cidade, construída depois da guerra dos Trinta Anos, não pode ser terminada até ıoo anos depois da Paz de Westfália.. ${ }^{33}$ Cem anos depois! Quase um século para se recuperar totalmente dessas guerras lamentáveis, para reconquistar um nível de desenvolvimento econômico e cultural razoavelmente elevado. No século XVI, a Alemanha foi um país muito rico, muito diversificado, com grandes cidades embelezadas durante o Ranascimento e que abarcavam todas as profissôes e casas comerciais como a dos Fugger $^{34}$, o banco privado mais desenvolvido do mundo nessa época e que financiou Carlos $\mathrm{V}$ em suas expediçôes. E tudo isso foi completamente destruído durante a guerra de 30 anos. Quase todas as grandes cidades foram destruídas. Em Würzburg, houve um grupo de historiadores paleógrafos, que traçaram o caminho que Gustavo Adolfo ${ }^{35}$ seguiu do Sul da Alemanha até a Suécia a partir da descoberta de livros encontrados em diferentes bibliotecas locais, os quais haviam sido roubados de grandes mosteiros de Würzburg e usados mais tarde para apoiar as rodas dos carros que afundavam na terra. Uma catástrofe enorme!

E destruiçôes do mesmo tipo ocorreram no século XX. Inicialmente, a catástrofe primordial de toda a Europa, a Primeira Guerra, que mais tarde estimulou um nacionalismo desenfreado a partir da humilhação sofrida pela Alemanha e que favoreceu a ascensão de Hitler. E a Segunda Guerra Mundial foi absolutamente desastrosa, não foi? Inclusive naquilo que nos toca, no nível intelectual e acadêmico. Imagine o estágio da física na Alemanha nos anos 20, início dos anos 30. Mas quase todos os grandes cientistas emigraram. Imagine também os grandes historiadores, historia- 
dores de arte e especialistas de numerosas outras disciplinas - incluindo a nossa na pessoa de Robert Ulrich - que emigraram para a Grã-Bretanha e os Estados Unidos. Imagine que, em 1945, os americanos confiscaram todo o acervo científico e tecnológico de patentes, direitos e marcas reunidos tanto na Secretaria Alemã de Patentes como em centenas de institutos de pesquisa, universidades técnicas e empresas industriais. A julgar pela recente pesquisa histórica ${ }^{36}$, os americanos pegaram- sob o título de "reparaçóes intelectuais" - todos os arquivos, todas as patentes com a proposta de compartilhá-las internacionalmente, mas, na verdade, eles só as usaram para potencializar suas próprias empresas. As estimativas desta gigantesca transferência de propriedade intelectual ascendem a Io.000 milhóes de dólares, em valores de 45/46. E com todas essas perdas, bem... todo o mundo acadêmico alemáo teve que se recuperar e se observarmos o tempo de restauração necessário após a Guerra dos 30 anos, você pode imaginar o que é necessário, o que é preciso para se reabilitar de uma destruição quase total do país. Não se consegue imaginar a destruição de grandes cidades como Hamburgo, como Colônia, como Frankfurt, como Berlim. Gigantesco. Neste sentido, tudo isso desempenha um papel muito interessante para explicar certa dependência intelectual no que se refere às universidades, ao mundo acadêmico, ao desenvolvimento da moda, dos estilos de vida, da vida cultural e recentemente se abriram possibilidades de se renovar em todo o mundo. A Europa, espero, pode recuperar um papel mais importante.

Entrevistadores: E este seria, a seu ver, um problema de América Latina? Esta dependência intelectual?

Jürgen Schriewer: Sim.

Entrevistadores: E a internacionalização que se promove hoje com muita força, poderia ser um problema nesse sentido?

Jürgen Schriewer: Parece-me interessante. Penso que é necessário que os países latino-americanos desenvolvam mais suas próprias tradiçóes, suas próprias ideias e nem sempre sigam exemplos estrangeiros sem consideraçôes mais profundas. Existe sempre o perigo de se usar o argumento in- 
ternacional. Não é conveniente. E o mito institucionalizado é usado nesse sentido, no sentido forjado pelos neoinstitucionalistas. Não é um mito, no sentido mais cotidiano da palavra, mas sim um modelo, um modelo definido, construído, aceito por muitos e que, desta forma, se eleva a um alcance normativo.

Entrevistadores: Em esse sentido, você fala que Bolonha...

Jürgen Schriewer: Sim, sim, nesse sentido, introduzi no título do capítulo do livro que lancei durante o Seminário: um mito neo-europeu ${ }^{37}$. É um mito, como expliquei durante o seminário. Estou convencido de que em 2050, Bolonha não existirá mais.

Entrevistadores: Professor Schiewer nosso tempo vai avançando e a conversa está muito boa.

Jürgen Schriewer: Já falamos demais, não? (risos)

Entrevistadores: Não, pelo contrário. O que você tem a nos dizer é muito útil. Mas queriamos fazer uma última pergunta. A iniciativa para a elaborar o convite para a sua vinda à Unisinos partiu do nosso Centro de Estudos Internacionais em Educação. Nós apreciariamos muito ouvir algumas sugestôes e recomendaçóes suas para o trabalho neste Centro. Como nós podemos desenvolver nosso trabalho?

Jürgen Schriewer: Bem, primeiro é necessário desenvolver investigações sérias e bem fundamentadas. E também se colocar a ênfase nas comparaçôes entre os países latino-americanos, já que os norte-americanos e outros continentes estâo olhando para a América Latina com um pouco de condescendência. As pesquisas devem ser realizadas por vocês, com todos os procedimentos metodológicos e teóricos, e com as fontes indispensáveis que vocês possuem, de forma que vocês possam construir um fundo de conhecimento incontornável e indispensável para todas as outras áreas acadêmicas. Isso é fundamental para se tornar um centro de pesquisas relevante e de grande reputação. Em seguida, vocês devem procurar fundos de financiamento de trabalho, se possível, para grandes projetos e que sejam 
duradouros. Não sei de qual órgão, o Conselho Nacional de Pesquisa, de pesquisas científicas ou a CAPES, ou outros fundos, um fundo de financiamento garantido. Além disso, também fortalecer o corpo de acadêmicos que trabalham nestas pesquisas, impulsionando doutorandos que sejam capazes de um trabalho sério e, talvez, estabelecer novos postos de professores para constituir uma equipe, uma série de medidas para desenvolver este centro. E o melhor, mais adequado e talvez mais fácil, penso, que seja tornar-se referência entre os diferentes países da América Latina, sempre levando em conta as tradiçóes linguísticas portuguesas e as castelhanas.

Entrevistadores: E inclusive, para nosso caso aqui, tradiçôes linguisticas de povos originários.

Jürgen Schriewer: Sim. Quechua ${ }^{38}$ acima de tudo. Completamente desconhecido.

\section{Entrevistadores: Professor Schiewer, muito obrigado por seu tempo e contribuiçôes. Esperamos tê-lo conosco em outras oportunidades.}

\section{Notas}

I O projeto contou com o apoio do CNPq. Por ocasião do seminário foi também lançado o livro de sua autoria Pesquisa em educação comparada sob condiçóes de interconectividade global. Sáo Leopoldo: Oikos, 2018.

2 Os aliados, ao derrotar a Alemanha Nazista, dividiram o território em quatro áreas de ocupação para finalidades administrativas e a linha de demarcação entre os setores de ocupação ocidental e o soviético foi acordada em um protocolo estabelecido na Conferência de Teerã (I943).

3 Região histórica da Alemanha, cujas fronteiras não são muito bem definidas, mas que compreende a região entre os Rios Reno e Weser, a norte da Bacia do Rio Ruhr.

4 Regiāo Oeste da Alemanha, compreendida pelas margens do Médio e Baixo Rio Reno.

5 King, E. Other Schools and Ours. London: Holt, Rinehart, and Winston. Primeira edição: 1958. Primeiro livro educacional de Edmund King, professor da Kings College de Londres, falecido em 1989 aos 87 anos, e que dedicou sua vida acadêmica à educação comparada.

6 Em alemão, Germanistik. Dentro das ciências humanas é a área de conhecimento acadêmica que pesquisa, registra e teoriza a língua e a literatura alemãs, de forma evolutiva ao longo do tempo histórico.

7 Filólogo alemão clássico e romanista, professor de literatura comparada na Universidade Rheinische Friedrich-Wilhelms, em Bonn e que fundou a Revista Arcadia (Revista Internacional de Estudos Literários) em 1966.

8 Universidade fundada em I402, cujo nome oficial é Bayerische Julius-Maximilians-Universität Würzburg, onde em I895 Wilhelm Röntgen descobriu o Raio X. 
9 Gottfried von Strassburg (Godofredo de Estrasburgo) foi um dos mais importantes poetas alemães medievais. Sua obra Tritão ( 2 Io), baseado na lenda Tristão e Isolda e escrito em alto alemão médio, possui mais de 19 mil versos e ficou inacabada, provalmente devido à sua morte.

ıo Família de dialetos do Alemão Alto, ramificação da Língua Germânica. O nome deriva das alianças dos clãs conhecidos como Alemani (foneticamente originado da expressão "all men”).

I I Região administrativa da França, fronteiriça com a Alemanha e Suíça, cuja capital é Estrasburgo.

I2 Exames de conclusão de curso, aplicados a todas as profissóes que demandam algum grau de qualificação, também chamados de Avaliação de Estado. Originalmente foi instituído na Prússia em i8i7.

I3 Esses conceitos estão desenvolvidos de forma aprofundada no livro: SCHRIEWER, J. Pesquisa comparada sob condiçóes de interconectividade global. São Leopoldo: Oikos, 2018. Especificamente para esses tópicos, sugere-se a consulta ao capítulos, "Ciência social comparada - problemas característicos e soluçóes cambiantes", p. 38-84, e capítulo 4, "O método comparativo e a necessidade de externalização: critérios metodológicos e conceitos sociológicos”, p.I3 I-I 82.

I4 Para a melhor compreensão do conceito sugere-se a leitura de HALL, P. e TAYLOR, R. As três versöes do neo-institucionalismo. Disponível em: http://www.scielo.br/pdf/ln/n58/aions8.pdf. Consultado em I5.06.2018.

I5 Historiador alemão, naturalizado americano (I934-2006), que emigrou para os EUA em I947, tendo lecionado nas Universidades de Harvard, Indiana, Boston e Pittsburg e também professor honorário em Georgetown.

I6 Academicamente, o termo alemão designa um livro em homenagem a uma pessoa influente ou reconhecida, normalmente um pesquisador ainda vivo. Contém contribuiçóes inéditas de colegas, ex-alunos, sendo publicado geralmente por ocasiáo da aposentadoria ou quando o homenageado completa 30 anos de carreira.

I7 Wilhem von Humboldt (I767-I835) foi funcionário público, diplomata, filósofo, fundador da Universidade de Berlim, amigo de Goethe e Schiller, conhecido pelas imensas contribuiçóes ‘filosofia da linguagem, à teoria e prática pedagógicas, influenciando também à filologia comparativa.

I8 O Tribunal Constitucional Federal (Bundesverfassungsgericht, ou BVerfG) é estabelecido pela Lei Alemã, e que está sediado na cidade de Karlsruhe e longe da sede do governo e de outros órgãos governamentais. Monitora com rigor a aderência das leis aos princípios constitucionais e tem contribuído para dar um caráter democrático ao estado alemão, embora com críticas à sua atuação, como as realizadas pela catedrática Ingeborg Maus em seu artigo "Judiciário como superego da sociedade: o papel da atividade jurisprudencial numa sociedade órfã”, disponível em: http://www.direitocontemporaneo.com/wp-content/uploads/20I4/o2/JUDICIÁRIOCOMO-SUPEREGO-DA-SOCIEDADE.pdf. Consultado em I5.06.2018.

I9 Gerhard Schröder, chanceler alemão de I998 a 2005.

20 Iniciativa para a Excelência é um programa do governo federal alemão em conjunto com seus dezesseis estados para incentivar as melhores universidades e instituiçóes de pesquisa. As mais bem conceituadas passam a contar com algum tipo de apoio financeiro governamental. Desde 20I2, onze universidades estáo no topo da avaliação.

2 I A Universidade Técnica de Munique (Technische Universität München, TUM) foi fundada em I868 pelo rei da Baviera, Luis II, como Escola Politécnica de Munique. Possui cerca de 20 mil alunos e foi a primeira a se expandir para o exterior (Instituto Alemão de Ciência e Tecnologia - GIST, em Cingapura)

22 A Universidade Ludwig Maximilian de Munique (Ludwig-Maximilians-Universität München - LUM) é uma universidade de pesquisa pública fundada em I 472 pelo Duque Ludwig IX e foi realocada diversas vezes em função das guerras. Possui 42 pesquisadores laureados com o Prêmio Nobel. É a segunda maior universidade na Alemanha em termos de alunos, aproximadamente 5 I mil alunos.

23 A Universidade Livre de Berlim (Freie Universität Berlin - FU Berlin) foi fundada em Berlim Ocidental durante o início da Guerra Fria e é uma das mais renomadas universidades da Ale- 
manha e da Europa. Possui caráter moderno e internacional e desenvolve pesquisa renomada na área das humanidades e das Ciências Sociais. Seu nome se origina do fato de ter sido sediada no lado considerado "livre" do Muro de Berlim, em contraposição ao lado controlado pela antiga Uniâo Soviética.

24 A Universidade Humboldt de Berlim (Humboldt-Universität zu Berlin) foi fundada em I8 го e é a mais antiga da cidade de Berlim. Foi fundada por Wilhem von Humboldt e seu modelo influenciou significativamente outras universidades europeias e ocidentais. Possui cerca de 37 mil alunos.

25 A Times Higher Education avalia as universidades no mundo todos os anos de acordo com seu desempenho em suas principais missóes: Ensino, pesquisa, transferência de conhecimento e alcance internacional. Segue abaixo a variaçáo das principais universidades alemâs de 2016 a 2018, a fim de explicar as flutuaçôes a que se refere o entrevistado.

$\begin{array}{lccc}\text { Times Higher Education Ranking - Alemanha - colocação } & & & \\ \text { Instituição } & 2016 & 2017 & 2018 \\ \text { Universidade Ludwig Maxmilian } & 29 & 30 & 34 \\ \text { Universidade Técnica Munique } & 53 & 46 & 4 \mathrm{I} \\ \text { Universidade de Heidelberg } & 37 & 43 & 46 \\ \text { Universidade de Humboldt } & 49 & 57 & 62 \\ \text { Universidade Técnica da Renânia do Norte- Westfália } & \text { IIO } & 79 & 78 \\ \text { Universidade de Freiburg } & 84 & 95 & 82 \\ \text { Universidade Livre de Berlim } & 72 & 75 & 88 \\ \text { Universidade Técnica de Berlim } & \mathrm{n} / \mathrm{c} & 82 & 92 \\ \text { Universidade de Tübingen } & 78 & 89 & 94 \\ \text { Universidade de Bonn } & 94 & \text { II3 } & \text { IOO } \\ \text { Universidade de Gottingen } & 99 & \text { II } 2 & \text { II } 3\end{array}$

26 O Instituto de Tecnologia de Karlsruhe (Karlsruher Institut für Technologie (KIT)) é uma universidade técnica, constituída em 2009 , através da fusão da Universidade de Karlsruhe, cujas origens remontam a uma Escola Politécnica fundada em I825, e do Centro de Pesquisa de Karlsruhe cuja expertise é na área de energia nuclear.

27 A Universidade de Heidelberg foi fundada em I386 por Ruperto I e é uma das mais prestigiadas da Alemanha. Passaram por ela 55 ganhadores do Prêmio Nobel.

28 A Universidade de Freiburg (Albert-Ludwigs-Universität Freiburg) é uma universidade publica, fundada em I457, pela Casa dos Habsburgos, É a quinta universidade mais antiga no país e I9 prêmios Nobel são associados a ela.

29 A Universidade de Tübigen (Eberhard Karls Universität Tübingen) é uma instituiçăo de ensino superior pública fundada em I 477 por Everardo I de Württemberg, que resolveu criar a universidade após viagens à Itália na época da influência Renascentista.

30 A Universidade de Göttingen (Georg-August-Universität Göttingen ou Georgia Augusta) foi criada em 1734 e, além de diversos prêmios Nobel associadas a ela, teve entre seus alunos diversas personalidades alemãs, tais como Wilhem e Alexander Von Humboldt, Otto Von Bismark e dois presidentes alemães, Gerhard Schröder e Richard von Weizsäcker, além do renomado Max Weber.

3I A Universidade Técnica de Dresden (Technische Universität Dresden ou TUD) possui mais de 36 mil estudantes e uma das mais amplas ofertas de cursos da Alemanha. Sua história remonta a mais de 200 anos, por ser uma das mais antigas escolas técnicas do país, embora somente exista como Universidade desde I96I.

32 Carlos Fuentes (1928-2012) foi escritor e diplomata mexicano. Romancista, novelista e ensaísta, foi professor em Harvard, Cambridge e Princeton. Recebeu diversos prêmios e reconhecimentos, 
entre eles: o Prêmio Miguel de Cervantes em 1987 e o Prêmio Príncipe de Astúrias em 1994.

33 A Guerra dos Trinta Anos (I6I8-I648) se refere genericamente a uma série de guerras travadas entre diferentes países da Europa e, em especial na Alemanha, cujas motivaçōes eram difusas e variadas, indo de rivalidades religiosas, entre dinastias, territoriais e comerciais. Os eventos deixaram um rastro de destruição econômica e demográfica e só foram encerrados com a assinatura de diversos tratados em bloco como a Paz de Westfalia, entre eles o de Münster e Osnabrück.

34 Os Fugger foram uma importante família alemã de banqueiros e comerciantes, entre o final da Idade Média e o começo da Idade Moderna. Financiaram missóes relevantes como as grandes navegaçôes e campanhas militares, tendo também importante papel político na época.

35 Gustavo Adolfo II (I594-I632) foi o Rei da Suécia durante 2I anos e liderou o país durante a Guerra dos 30 Anos, na qual apoiou os protestantes do Norte contra os católicos do Sul, auxiliando no equilíbrio do poder político e religioso da Europa. É considerado um grande comandante militar e seu exército sueco era caracterizado por armas de qualidade, excelente treinamento e efetivo apoio de artilharia.

36 John Gimbel: Science, Technology, and Reparations: Exploitation and Plunder in Postwar Germa$n y$ (Stanford University Press, I990).

37 Referência ao livro SCHRIEWER, J. Pesquisa comparada sob condiçôes de interconectividade global. São Paulo: Oikos, 2018. Especificamente ao capítulo 7: "Bolonha - um mito neo-europeu?"

38 O quéchua é uma família de línguas indígenas, muito importante na América do Sul, e ainda falada por aproximadamente ro milhóes de pessoas de diferentes grupos étnicos da Argentina, Chile, Colômbia, Equador, Bolívia e Peru, sendo uma das línguas desses três últimos países. 